\title{
LA ACADEMIA DE TLÖN. NOTAS SOBRE BORGES ${ }^{1}$
}

\section{THE ACADEMY OF TLÖN. NOTES ON BORGES}

\author{
Î́ñigo LARRAURI GÁRATE \\ Universidad del País Vasco / EHU \\ larrauri_@hotmail.com
}

Resumen: Este trabajo estudia la actividad crítica de Borges y sus distintas etapas de desarrollo. Se ocupa también de la técnica utilizada en sus primeros textos narrativos (Historia universal de la infamia, Ficciones) para, a continuación, establecer ciertas relaciones entre las operaciones borgianas y algunas tendencias analíticas que abundan en la crítica académica de nuestros días.

Palabras clave: Borges. Análisis. Influencia. Crítica académica.

Abstract: This paper studies the critical activity of Borges and its various stages of development. It also deals with the technique of his early narrative (Historia universal de la infamia, Ficciones). Then, we will establish some relationships between Borgean creative techniques and some analytical trends which are common in current academic criticism.

Key Words: Borges. Analysis. Influence. Academic criticism.

1 Este trabajo comunicación se ha llevado a cabo dentro del Grupo de Investigación GIU 13/21 (2013-2016), MAC (Mutaciones del Audiovisual Contemporáneo) de la Universidad del País Vasco / Euskal Herriko Unibertsitatea (UPV/EHU). 
"Hablaré de él con la licencia que mi admiración me confiere" Jorge Luis Borges

("El Ulises de Joyce", Inquisiciones)

\section{PARA EMPEZAR...}

Una de las escenas centrales de la narrativa de Borges es la del duelo, instante fatal en el que muchos de los personajes que pueblan sus relatos se ven obligados a esclarecer, en una disputa a cuchillo, el sentido último de sus cortas historias. Obviamente, no hay duelo sin dos partes enfrentadas, y esta discusión se produce también, así lo entiendo al menos, entre distintas facetas del propio Borges. Tenemos al creador; tenemos al crítico. El creador incluye en su seno al poeta y al narrador; este, a su vez, a lo largo de su obra, se bifurca en dos vetas: por un lado, aquellos relatos dominados por malevos, arrabales y profesionales del truco; $y$ por otro, las narraciones plagadas de sospechosas referencias eruditas, falsos índices y maliciosas notas al pie².

También dentro del Borges crítico se adivina cierta división o, al menos, un vaivén entre dos concepciones de la literatura: en sus primeras notas críticas, aquellas que componen los libros Inquisiciones (1925), El tamaño de mi esperanza (1926) y El idioma de los argentinos (1928), es palpable una mayor preocupación por la materialidad de los textos y por determinar sus mecanismos de sentido, preocupación que irá decreciendo a lo largo de su obra hasta desembocar en una idea de la literatura que delega su peso en el lector, idea brillantemente expresada en el artículo, incluido en Otras Inquisiciones (1952), “Notas sobre (hacia) Bernard Shaw" (1951):

[...] El libro no es un eje incomunicado: es una relación, un eje de innumerables relaciones. Una literatura difiere de otra, ulterior o anterior, menos por el texto que por la manera de ser leída: si me fuera otorgado leer cualquier página actual —esta, por ejemplo — como la leerán en el año 2000, yo sabría cómo será la literatura del año 2000 (Borges, 2011a: 342).

Así pues, antes de llegar a este límite, en la primera etapa del Borges crítico podemos encontrar textos como "Acerca de Unamuno, poeta" (Inquisiciones, 1925) donde señala que "[...] si la desconfianza de algún lector me refuta juzgando que la poesía es cosa que solicita nuestra gustación y no nuestro análisis, le responderé que todo en el mundo

2 Estas dos líneas de su narrativa han sido puestas en relación por distintos autores (Jon Juaristi, Ricardo Piglia, Alan Pauls), siguiendo pistas evidentes que el propio Borges ha anotado en distintas partes de su obra, con sus dos linajes familiares: el paterno, como origen de la línea conceptual; y el materno, de ascendencia militar, como punto de partida de esa otra línea que podríamos denominar la épica del arrabal. 
es digno quebradero de la inteligencia" (Borges, 2011a: 98), o "Ejercicio de análisis" (EI tamaño de mi esperanza, 1926), en el que escribe: "[...] Creo en la entendibilidá final de todas las cosas y en la de la poesía, por consiguiente. No me basta con suponerla, con palpitarla; quiero inteligirla también" (Borges, 1994: 99). Y para inteligirla propone su método: "[...] Analicemos con prolija humildá y pormenorizando sin miedo" (Borges, 1994: 100).

En estos y otros textos de sus primeros libros, elige un poema, lo desmenuza, analiza después los versos, indagando la sedimentación de significados que esconde cada epíteto, comprobando hasta qué punto la necesidad de la rima impone una expresión ajena a la que el sentido del verso exige; en esta minuciosidad del análisis se refleja un interés por la técnica y un afán por la entendibilidá. Sucede sin embargo que la pormenorización de Borges es probablemente excesiva, a tal punto que acaba por incurrir en algo así como un microanálisis interesado. Porque no trata tanto de comprobar el funcionamiento de un poema, como de elegir del poema en cuestión unos versos que permitan esbozar una concepción de la literatura como hija casi exclusiva del tiempo. Señala por ejemplo en el citado texto sobre Unamuno, poeta:

[...] Estoy seguro de que voces como inmortal o infinito no fueron en su comienzo sino casualidades del idioma, abusos del prefijo negativo, horros de sustancial claridad. Tanto los hemos meditado y enriquecido de conjeturas que ayer necesitamos de una teología para dilucidar la primera y aún nuestros matemáticos disputan acerca de la segunda (Borges, 2011a: 100).

Con esta idea en mente acomete también el "Examen de un soneto de Góngora" (incluido en El tamaño de mi esperanza), para concluir con una opinión no sobre el soneto únicamente, sino sobre la literatura. Así, después de advertir en los versos del poeta “[...] sus aciertos posibles y sus equivocaciones seguras", Borges admite: "[...] Yo he querido mostrar en la pobreza de uno de los mejores, la miseria de todos" (Borges, 1994: 115).

En su cuarto libro de ensayos, Discusión (1932), esta idea de analizar pormenorizando sin miedo pervive en algunos textos como "El arte narrativo y la magia" (1932), pero en otros artículos del mismo volumen, como "La supersticiosa ética del lector" (1930), se critica a aquellos que "[...] no se fijan en la eficacia del mecanismo, sino en la disposición de sus partes" (Borges, 1985: 137) y se afirma sin temor alguno que "[...] La economía prosódica no es menos forastera del arte que la caligrafía o la ortografía o la puntuación: certeza que los orígenes judiciales de la retórica y los musicales del canto nos ocultaron siempre" (Borges, 1985: 140)3. Son dos posiciones casi contrarias, de nuevo un duelo.

3 Considerar la puntuación "forastera del arte" es, desde luego posición alejada del riguroso análisis. Como modélico ejemplo de este, citamos unas líneas del justamente reconocido examen que Claude Lévi-Strauss 
Recordemos a Menard, y la curiosa habilidad que Borges le imputaba: "[...] su hábito resignado o irónico de propagar ideas que eran el estricto reverso de las preferidas por él" (Borges, 2013: 115). La pregunta que nos surge es cuál de estas dos ideas de la crítica es la preferida por Borges: pormenorizar con detalle los versos de un poema para ver su funcionamiento (aunque sea como paso previo para sostener una posición determinada) o, por el contrario, olvidarse de la disposición y del mecanismo para valorar únicamente su efecto en el lector. No es fácil distinguir la preferencia y su reverso en alguien que apuntaba, defendiendo a Menard de sus detractores, que "[...] la ambigüedad es una riqueza" (Borges, 2013: 115).

En cualquier caso, esta ambivalente posición de Borges parece decantarse hacia el lado del lector tras la aparición de Ficciones (1944), como si precisamente con "Pierre Menard, autor del Quijote" (1941) su autor tomara partido definitivamente por la importancia de la recepción de la obra más allá del análisis de su funcionamiento interno ${ }^{4}$. En adelante, Borges convertirá en la base de creación de sus relatos conceptuales una posición de lectura similar a la de los extraños metafísicos del imaginario planeta de Tlön que, como se recordará, leían la metafísica como si fuera una rama de la literatura fantástica; es decir, leían desde una posición de lectura no prevista o no prescrita por el texto.

\section{CORRESPONDENCIAS}

Es estrategia habitual en Borges dotar a sus ficciones de verosimilitud dándoles la forma de un relato que es escuchado por él y posteriormente narrado a nosotros. Escuchado o leído, tal como sucede en esa parte conceptual de su narrativa que componen Almotásin, Menard y otros, y que discurre no lejos de Tlön. La enciclopedia donde figura la entrada Uqbar, el célebre catálogo que recoge los proyectos de Menard que sólo sus amigos vieron con alarma y "aun con cierta tristeza": documentos que

y Roman Jakobson realizaron del poema de Baudelaire "Los gatos" ("Les chats", Le Corseire, 14/11/1847), en el que reparan con detalle (también) en la puntuación:"[...] en el texto del Corsaire (1847) la puntuación del soneto corresponde a esta división. El primer terceto termina con un punto, así como el primer cuarteto. En el segundo terceto y el segundo cuarteto los dos últimos versos van precedidos de punto y coma..." (Jakobson, 1977: 158).

4 En un esmerado estudio que trata con mayor sosiego de dividir las diferentes etapas de la labor crítica de Borges, Herminia Gil Guerrero admite la ambivalencia de su posición todavía en 1941. Así, el mismo año que escribe el Menard, Borges, en el prólogo a la Antología poética argentina, realizada junto a Silvina Ocampo y Adolfo Bioy Casares, señala: "[...] Más importante que los temas de los poetas y que sus opiniones y convicciones es la estructura del poema: sus efectos prosódicos y sintácticos" (Borges, 1941: 9-10; citado por: Gil Guerrero, 2008: 21-22). El propio Borges apuntaba en su epílogo de El Hacedor (1960) que los materiales en él compilados incluían "[...] piezas pretéritas que no me he atrevido a enmendar, porque las escribí con otro concepto de la literatura" (Borges, 2012: 146), en cierta forma admitiendo los cambios de su idea de la literatura a lo largo de los años. 
solo Borges ha visto y que nos transmite después ${ }^{5}$. Con este método se sitúa al lector en un estado hibrido; en una incredulidad ante unos personajes excesivos, atenuada por la verosimilitud que otorga a sus breves historias esa referencia al documento que estructura el marco en el que son narradas. Aunque Menard es el de mayor fama entre la cohorte de desmedidos borgianos y su caso el más estudiado, el preludio de esta forma de hacer puede observarse ya en Historia universal de la infamia (1935).

Como se recordará, el volumen reúne nueve textos —el último de los cuales, intitulado "Etcétera", está compuesto de seis textos breves-, y una bibliografía. Excepción hecha de "Hombre de la esquina rosada", diría que lo textos no se ajustan a lo que convencionalmente entendemos como relatos de ficción. Los primeros siete textos son historias tomadas por Borges de distintos libros, cuidadosamente seleccionadas, desfiguradas, resumidas y reescritas por él. Esos libros de origen o fuentes son los que figuran en la bibliografía final, indicando de cuál de ellos bebe cada cuento. En esa bibliografía se incluyen, sobre el séptimo de los textos, “El tintorero enmascarado Hákim de Merv", dos referencias bibliográficas, una cierta y una falsa: "A History of Persia, de Sir Percy Sykes, Londres, 1915" y "Die Vernichtung der Rose, Nach dem arabischen Urtext übertragen von Alexander Schulz, Leipzig, 1927", respectivamente. Como puede verse, las referencias cumplen los requisitos exigidos por el género bibliografía: título, autor, lugar y fecha de publicación. En principio, incluir una referencia falsa entre varias verdaderas es una maniobra aparentemente sencilla; sin embargo, encierra un malicioso ataque a ese marco de verificación que es toda bibliografía. La referencia, colocada además en último lugar, aumenta la posibilidad de que el lector interesado, tras haber comprobado la existencia de las referencias anteriores, relaje su sospecha ante la última ${ }^{6}$. Podría pensar

5 Así sucede ya en el relato inaugural de esa línea conceptual, “El acercamiento a Almotásin” (1935), incluido en la recopilación de ensayos que componen Historia de la eternidad (1936). Sobre el efecto producido por este cuento no deja lugar a dudas la anécdota protagonizada por Bioy Casares (Pauls, 2004: 117), que llegó a encargar la compra de un ejemplar de "[...] la novela The approach to Al-Mu'tasim del abogado Mir Bahadur Alí, de Bombay" (Borges, 2011 b: posición 1364) que obviamente solo existía en la imaginación (y en la obra) de Borges. Que el autor incluyera esta reseña ficticia en un libro de ensayos no parece acción inocente (nada parece inocente en Borges), sino táctica para fomentar el, llamémosle así, "efecto de verdad".

6 Por otra parte, tenemos ese relato noveno del libro que bajo el título "Etcétera" recoge seis historias. Estas incluyen, al final de cada una de ellas, entre paréntesis, una mención a la obra en que se basan; "(De Vera Christiana Religio, 1771, de Emanuel Swedenborg)", por ejemplo, figura al final del breve relato de esa sección "Un doble de Mahoma". Como puede verse, a diferencia de las referencias de la bibliografía, estas no son completas e incluyen delante del título un "De", que puede entenderse como "tomado de". Con este tipo de mínimos gestos Borges señala que la relación que estas referencias mantienen con el texto que las precede es distinta a la que las obras que figuran en la bibliografía sostienen con los primeros siete textos del libro. 
incluso en una errata involuntaria en el título que dificulta su localización, o que se trata de una obra descatalogada, quién sabe.

Creo entrever en estas prácticas del primer libro de narrativa de Borges una especie de laboratorio de pruebas de la técnica que aplicará más tarde en el Menard, y que bien podría explicarse alterando una expresión de Coleridge que Borges citaba con frecuencia: la suspensión de la incredulidad. Así definía el poeta inglés el instante en el que el lector deja de cuestionar la veracidad de la historia, limitándose durante ese tiempo a seguirla con atención. En Borges sucede justamente lo contrario: la suspensión de la credulidad'. Y ello porque lo inverosímil y fantástico de las peripecias relatadas cuestiona el espacio en el que las historias discurren: un marco que asociamos con un registro serio, fidedigno; un marco que investimos como portador de una verdad insinuada por la propia inclusión de las referencias bibliográficas que podrían discutirla. Así, por un lado, dando cuenta de un documento inverosímil y sus derivas, y por otro, utilizando un sistema fiable (la bibliografía, pero también la nota al pie, el catálogo, la enciclopedia, la biblioteca en última instancia), los relatos conceptuales de Borges probablemente persiguen y desde luego consiguen la suspensión de la credulidad: lo leemos con permanente sospecha ${ }^{8}$.

En este punto podrían señalarse algunas correspondencias con cierta forma de entender el análisis y examen de la obras de ficción que en el mundo académico llevan ya un tiempo en auge, y a las que me referiré con la generalizadora etiqueta de Estudios Culturales. Obviamente, no digo nada nuevo: ya otros se han ocupado de señalar que "[...] una zona muy dominante de la crítica académica es hoy básicamente borgeana, trabaja sobre el camino abierto por Borges" (Piglia, 2001: 169). Asegura el tránsito por ese camino el marco en que este se inscribe. Es decir, ese marco que Borges utilizaba para alterar la forma de leer su texto y ponerlo bajo sospecha ante el lector, funciona hoy como salvoconducto que otorga marchamo académico a una serie de estudios que no siempre lo merecerían, en tanto que dejan de lado el análisis literal de las obras (que desde luego no es el único pero si el principal) para demostrar los significados ocultos que, al parecer, todos los demás no acertamos a ver. A fuerza de repetirse, la creciente bibliografía en esta línea parece ir creando un corpus que fija estos sentidos ocultos como principales, tratando de convertir los objetos de estudio en documentos ilustrativos de represiones de minorías étnicas o ubicuos complejos de Edipo, complejos y represiones presentes in absentia. A Dios gracias, tenemos la suerte de contar con los objetos (que sobreviven, a

7 Inversión de la fórmula que Pauls ha sabido ver desde un ángulo distinto (Pauls, 2004: 138).

8 Entiendo que, al menos, así lo lee su lector modelo. Probablemente exista también un lector crédulo que dé por buenas las referencias que Borges incluye en sus textos, pero al no comprobar la existencia real de estas no completa la lectura y, por tanto, no se trata del lector prescrito por el texto. Además, el lector crédulo no contempla la existencia del lector incrédulo mientras que este, por el contrario, comprende la posible existencia de un lector menos sagaz o curioso. 
diferencia del Quijote de Menard) para discutir las interpretaciones, algunas divertidas y escritas con un desparpajo notorio, es de ley admitirlo. A mi modesto entender se trata de unas interpretaciones que están en la línea de Borges, con la diferencia insalvable de que las de este no llevaban el sello de University Press alguna, ni el beneplácito de la academia.

No es esta una cuestión menor. Porque siendo cierta esta correspondencia entre la posición de lectura de la corriente académica a la que he hecho alusión y Borges, me parece que en los textos más conceptuales de este podemos encontrar también el antídoto o prevención para leer los textos a los que me estoy refiriendo. Cierto es, como se ha dicho, que parte de la particularidad del efecto que estos relatos borgianos provocan en el lector nace de la inclusión en ellos de referencias bibliográficas que dan a los textos una apariencia de verdad que entra en contraste con lo inverosímil de las historias relatadas; sin embargo, si atendemos a las referencias con detalle, pronto veremos que algunas son falsas, quedando así en evidencia lo artificioso del dispositivo, que nos incita entonces a dudar de las referencias verdaderas y de todo el conjunto.

Este peculiar y en cierta forma paradójico funcionamiento de los artefactos borgianos ${ }^{9}$ me lleva a pensar en una reflexión que Claude Lévi-Strauss planteaba a propósito de otra cuestión, quizá no tan alejada como pudiera parecer. En una conocida entrevista con Georges Charbonnier, el antropólogo francés hacía notar lo siguiente:

\section{[...] El academicismo de la pintura preimpresionista era, para utilizar el} lenguaje de los lingüistas, un academicismo del significado: los objetos mismos -rostro humano, flores, jarrón- que se quería representar eran vistos a través de una convención y de una tradición, mientras que con esa profusión de maneras que vemos aparecer en cierta época, en cierto momento, entre los creadores contemporáneos, el academicismo del significado desaparece, pero para dar paso a uno nuevo que yo llamaré el academicismo del significante. [...] El academicismo de lenguaje reemplaza al del asunto (Charbonnier, 2006: 87).

9 Artefactos que, en cierta forma, podrían considerarse como ready-mades en prosa. Ya Alan Pauls apuntaba en esta dirección al calificar el arte de Borges como no retiniano (Pauls, 2004: 118). En este sentido podríamos rescatar la reflexión de Lévi-Strauss (Charbonnier, 2006: 103) cuando señalaba que el readymade está necesariamente compuesto por dos elementos: el objeto y el contexto en el que se inserta para poder ser visto. También los relatos borgianos pueden entenderse de esta forma: como artefactos compuestos por el cuento en sí y las referencias bibliográficas a otros textos (ciertas o no) que permiten que su propuesta o la idea que encarnan sea vista. Con el añadido de que la excepcional prosa de Borges ayuda al ocultamiento de la idea principal: bajo la apariencia de un gran escritor, que sin duda lo es, se encuentra, creo, un artista conceptual. 
Me pregunto si podría incurrir en una extrapolación flagrante y considerar el análisis académico de un objeto artístico como un significado y el sistema de referencias que lo sostiene como un significante. Si nos permitiéramos tal licencia, ¿no podría leerse el aparataje académico como un caso de academicismo del significante? Visto así, el sistema de notas, bibliografía, etc., ¿acaso no camufla, en ocasiones, unas interpretaciones que, de prescindir de él, podrían atribuirse a un mal imitador de Borges? Como en su caso, estaríamos ante una forma de leer que niega que haya jerarquías de significados en el interior de los textos, que lee sus márgenes como si fueran su centro, centro de cuya existencia reniega previamente. Pero insistamos en señalar la diferencia: en Borges, la lectura literal de los textos queda arrinconada en beneficio de una lectura literaria ${ }^{10}$; en los textos académicos aludidos, en beneficio de lo que podríamos llamar una lectura litoral: lectura ubicada en ese espacio de transición entre la costa o frontera del texto y un mar de ilimitados contextos que generaran infinitos sentidos; punto de contacto entre ambos espacios que aparenta tener los pies en tierra firme (la tierra de la academia, del método, de la referencia), mientras navega a contracorriente del sentido literal ${ }^{11}$. Bien podría decirse de los integrantes de esa expedición lo que Borges de los metafísicos de Tlön: "[...] no buscan la verdad ni siquiera la verosimilitud: buscan el asombro" (Borges, 2013: 98).

\section{ETCÉTERA (CODA BORGIANA)}

Luciano Cepeda era su nombre. Le esperaban en su barrio desde hacía años. De él se decían injurias para resaltar el valor de su voz. Los pocos que la habían oído aseguraban que con un quejío era capaz de invocar una herencia perdida; de despertar remotos orígenes. Cuando entonaba su temida petenera todos callaban admirados. Como el resonar de un coro de bandidos últimos, en cada actuación de Cepeda susurraban las voces de los más ilustres

10 Como Umberto Eco señala en su artículo "La abducción en Uqbar": "[...] El universo de Borges funciona según las leyes de la puesta en escena o de la ficción". Es decir: "[...] Sus leyes no son las de la ciencia neopositivista, son leyes paradójicas. La lógica (la misma) de la Mente y la del Mundo son ambas una ilógica. Una ilógica férrea. Solo con esa condición puede Pierre Menard reescribir 'el mismo' Don Quijote. Pero, ay, solo con esa condición el mismo Don Quijote será un Don Quijote diferente (Eco, 2012: posición 3058).

11 En este punto señalamos, de nuevo con Eco, lo siguiente: “[...] La iniciativa del lector consiste en formular una conjetura sobre la intentio operis. Esta conjetura debe ser aprobada por el conjunto del texto como un todo orgánico. Esto no significa que sobre un texto se pueda formular una y solo una conjetura interpretativa. En principio se pueden formular infinitas. Pero, al final, las conjeturas deberán ser probadas sobre la coherencia del texto, y la coherencia textual no podrá sino desaprobar algunas conjeturas aventuradas (Eco, 2013: 51). 
emisarios del jondo. Lo esperaban desde siglos a Cepeda. El hombre que era todos los hombres del barrio del cante.

Por más que la cursiva incline la letra, a nadie habré hecho creer que estas líneas intolerables procedan del impar Borges, y si me he atrevido a escribirlas es sólo para poder dar cuenta ahora del texto que me las sugirió.

Por razones que no vienen al caso, hace un tiempo cayó en mis manos Flamenco. Pasión, política y cultura popular, del profesor William Washabaugh. En sus primeras páginas encontré la siguiente revelación:

[...] Las interpretaciones de arriba abajo tratan de explicar los géneros desde sus orígenes hasta sus condiciones actuales mediante la descripción de procesos evolutivos y la periodización de fases de desarrollo. [...] El principal problema que presentan las interpretaciones de arriba abajo es el "objetivismo abstracto." [...] Así pues, éste es el reto al que se enfrenta la presente obra: evitar que los árboles nos impidan ver el bosque del flamenco y, al hacerlo, tener en cuenta el hecho de que la música flamenca no es tanto una herencia de pasado sino algo que se fabrica continuadamente en el presente. Cada nueva actuación reestructura todo lo que la ha precedido. Pese a que una melodía, una letra o un ritmo parezcan provenir de artistas del pasado, siempre sufren algún tipo de transformación durante la ejecución. Se recrean en y a través de sus contextos novedosos de su producción y audición. [...] fuera de Andalucía el flamenco obra de otro modo (Washabaugh, 2005: 18-21).

En su momento creí detectar aquí varios ingredientes de la técnica borgiana, como el cambio de significado de una melodía, letra o ritmo en función del contexto, o la permanente renovación y reestructuración de la historia del cante en cada actuación. Lo cierto es que sigo encontrando semejanzas, pero lo que aplaudo en la ficción me inquieta en el estudio. $Y$ no quiero decir con ello que considere que cada cante $u$ otro objeto de análisis deba ser interpretado como el último episodio de una historia debidamente periodizada, pero sí que cada objeto de análisis o cante remite a una parte de su historia, que reclama ser activada. No sé de otra forma que conocerla, estudiarla, para saber cuál es el segmento pertinente de esa historia; cuál el que debe tomarse en cuenta para descifrar correctamente el mensaje del objeto. Pero probablemente responda esto a una concepción caduca sobre cómo proceder para examinar objetos y textos, cuando no a una torpe lectura de los comentados en las páginas antedichas. En ellas, a buen seguro, habré incurrido en obviedades, repetido errores antiguos y añadido algunos nuevos. En mi defensa sólo puedo cerrar este texto parafraseando al desdichado protagonista de 
"La forma de la espada" (1942)", el infame John Vincent Moon: Le he narrado la historia de este modo para que usted la oyera hasta el fin. Yo soy el autor de estas páginas. Ahora desprécieme.

\section{REFERENCIAS BIBLIOGRÁFICAS}

BORGES, J. L.; OCAMPO, S. y BIOY CASARES, A. (1941). Antología poética argentina. Buenos Aires: Sudamericana.

BORGES, J. L. (1985). Prosa completa, 1. Evaristo Carriego. Discusión. Historia universal de la infamia. Barcelona: Bruguera.

(1994). El tamaño de mi esperanza. Barcelona: Seix Barral.

(2011a). Inquisiciones/Otras inquisiciones. Barcelona: Debolsillo.

(2011b). Historia de la eternidad. Barcelona: Debolsillo (edición Kindle). (2012). El hacedor. Barcelona: Debolsillo. (2013). Cuentos completos. Barcelona: Debolsillo.

CHARBONNIER, G. (2006). Entrevistas con Claude Lévi-Strauss. Buenos Aires: Amorrortu. ECO, U. (2012). De los espejos y otros ensayos. Barcelona: Debolsillo (edición Kindle). (2013). Los límites de la interpretación. Barcelona: Debolsillo.

GIL GUERRERO, H. (2008). Poética narrativa de Jorge Luis Borges. Madrid: Iberoamericana. JAKOBSON, R. (1977). Ensayos de poética. Madrid: Fondo de Cultura Económica.

PAULS, A. (2004). El factor Borges. Barcelona: Anagrama.

PIGLIA, R. (2001). Crítica y ficción. Barcelona: Anagrama.

WASHABAUGH, W. (2005). Flamenco. Pasión, política y cultura popular. Barcelona: Paidós. 